\title{
GREEN TEA IN TRANSDERMAL FORMULATION: HPLC METHOD FOR QUALITY CONTROL AND IN VITRO DRUG RELEASE ASSAYS
}

\author{
Michele Campos Alvesa, Priscila Aparecida de Almeida ${ }^{a}$, Hudson Caetano Poloninia ${ }^{a}$ Nádia Rezende Barbosa Raposo ${ }^{a}$, \\ Anderson de Oliveira Ferreira ${ }^{\mathrm{b}}$ and Marcos Antônio Fernandes Brandão ${ }^{\mathrm{a}, *}$ \\ ${ }^{a}$ Núcleo de Pesquisa e Inovação em Ciências da Saúde, Faculdade de Farmácia, Universidade Federal de Juiz de Fora, Rua José \\ Lourenço Kelmer, s/n, 36036-330 Juiz de Fora - MG, Brasil \\ 'Laboratório de Controle de Qualidade, Ortofarma, 36120-000 Matias Barbosa - MG, Brasil
}

Recebido em 25/06/2013; aceito em 06/01/2014; publicado na web em 27/03/2014

\begin{abstract}
RP-HPLC based analytical method for use in both quality control of green tea in a semisolid formulation and for in vitro drug release assays was developed and validated. The method was precise $(\mathrm{CV}<5 \%)$, accurate (recovery between $98 \%$ and $102 \%)$, linear $\left(\mathrm{R}^{2}\right.$ $>0.99$ ), robust, and specific for the determination of epigallocatechin 3-gallate (EGCG), caffeine (CAF), and gallic acid (GA). In a diffusion cell chamber, the release rate of EGCG was $8896.01 \mu \mathrm{g} \mathrm{cm}^{-2}$. This data showed that EGCG will be able to exert its systemic activity when delivered though the transdermal formulation, due to its good flux rates with the synthetic membrane.
\end{abstract}

Keywords: Camellia sinensis; quality control; in vitro drug release.

\section{INTRODUCTION}

Green tea is produced by steaming and drying the leaves of Camellia sinensis (Theaceae), an evergreen shrub mainly cultivated in Japan, India, China, and Sri Lanka. ${ }^{1}$ It is characterized by the presence of huge amounts of polyphenols, the majority of them being catechins. Current scientific evidence associates these molecules with antioxidant, antimutagenic, anticarcinogenic, and antibacterial properties; ${ }^{2}$ these are used as agents in the prevention of obesity, hypertension, and diabetes as well as in the reduction of cardiovascular-disease risk and as protection against ultraviolet solar radiations. ${ }^{3}$

In the analytical context, the determination of marker compounds in herbal medicines is of commercial value to ensure the quality of the medicine. ${ }^{4}$ Thus, catechins in green tea, represented by: $(+)$-catechin (C), (-)-epicatechin (EC), (-)-catechin 3-gallate (GCG), (-)-epicatechin 3-gallate (ECG), (-)-gallocatechin (GC), (-)-epigallocatechin (EGC), (-)-gallocatechin 3-gallate (GCG), and epigallocatechin 3-gallate (EGCG) (Figure 1) have merged as potential markers. EGCG, which is generally the most abundant and active component, is usually used as a green tea biomarker. ${ }^{5}$

Caffeine (CAF) content (about $2.5 \%-3.5 \%$ of dry weight) ${ }^{2}$ is also an important quality parameter. The content of CAF in the green tea extract is regulated, as it is associated with diuretic responses and can affect the action of some drugs. ${ }^{6} \mathrm{CAF}$ also influences central nervous system activity ${ }^{7}$ and is responsible for the harmful effects associated with green tea overconsumption. Higher doses of CAF $\left(>200 \mathrm{mg} \mathrm{day}^{-1}\right.$ ) can cause anxiety, headache, nervousness, tremors, sleeplessness, increase in blood pressure, and so forth. ${ }^{2}$ Green tea also contained phenolic acids such as gallic acid (GA) $)^{8}$-a product of degradation derived from galloyled catechins-whose content should be limited. ${ }^{9}$ The remaining solids in green tea include: theanine, theaflavins, theorubigins, quercetin, and chlorogenic acid. ${ }^{7}$

Green tea is widely ingested orally, but can also exert its biological activities when applied topically. Many topical formulations of green tea are commercially available, where $\sim 65 \%$ of the patent applications are for cosmetics (skin care) ${ }^{10}$ With regard to the transdermal systems, there is still a challenge; catechins have low skin

*e-mail: marcosbrand2012@gmail.com<smiles>[R6]OC1Cc2c(O)cc(O)cc2OC1c1cc([R])c(O)c(O)c1</smiles><smiles>Cn1c(=O)c2c(ncn2C)n(C)c1=O</smiles>

Epicatechin: $\mathrm{R}_{1}=\mathrm{R}_{2}=\mathrm{H}$

Epigallocatechin: $\mathrm{R}_{1}=\mathrm{OH}, \mathrm{R}_{2}=\mathrm{H}$

Epicatechin 3-gallate: $\mathrm{R}_{1}=\mathrm{H}, \mathrm{R}_{2}=$ Galloyl

Epigallocatechin 3-gallate: $\mathrm{R}_{1}=\mathrm{OH}, \mathrm{R}_{2}=$ Galloyl<smiles></smiles>

Catechin: $\mathrm{R}_{1}=\mathrm{R}_{2}=\mathrm{H}$

Caffeine

Gallocatechin: $\mathrm{R}_{1}=\mathrm{OH}, \mathrm{R}_{2}=\mathrm{H}$

Catechin 3-gallate: $\mathrm{R}_{1}=\mathrm{H}, \mathrm{R}_{2}=$ Galloyl

Gallocatechin 3-gallate: $\mathrm{R}_{1}=\mathrm{OH}, \mathrm{R}_{2}=$ Galloyl<smiles>O=C(O)c1cc(O)c(O)c(O)c1</smiles>

Gallic acid

Figure 1. Structures of the major catechins, caffeine and gallic acid presents in green tea

permeability due to their hydrophilic nature and chemical interaction with skin lipid bilayers. ${ }^{11}$

Several researchers have studied the cutaneous permeation profiles of catechins in topical formulations and they have shown that the main active component (EGCG) has limited penetration through human skin. ${ }^{12-15}$ However, its passage through skin could be improved by incorporating it into transdermal vehicles. ${ }^{11}$ In addition, a transdermal drug could give consumers an alternative delivery mechanism (Scheme 1), wherein the first-pass hepatic metabolism of catechins is avoided. ${ }^{12,16}$

Consequently, green tea extract (GTE) can be incorporated into a new formulation. Moreover, it is desirable that these formulations provide good skin permeation and systemic absorption. In order to develop a new formulation, it is necessary to assess the quality of the bio-active molecules. Among the specific tests conducted for 


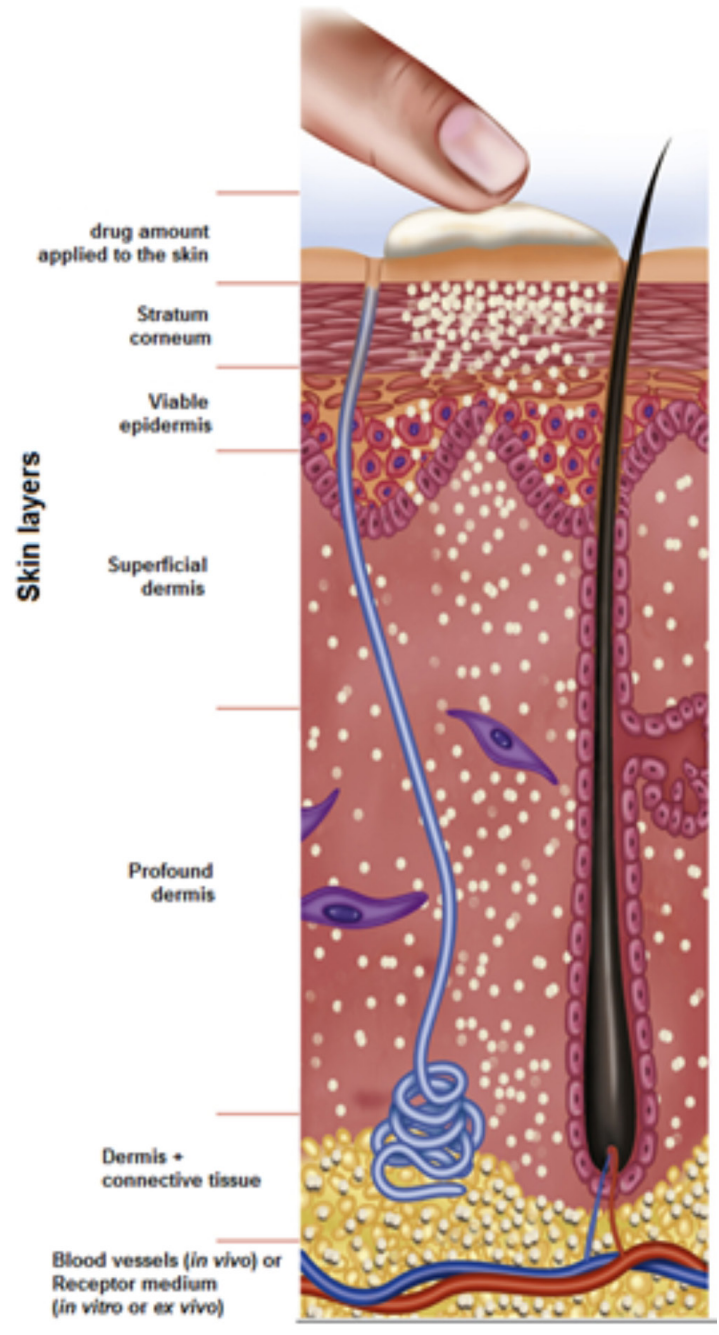

Scheme 1. Schematic representation of skin layer and the transdermal system application

the quality assessment of transdermal emulsions, ${ }^{17}$ the in vitro drug release carried out in Franz-type diffusion cell is widely used. Such a test can estimate the release of drugs from semisolid systems into synthetic skin and predict the percutaneous systemic absorption of topically applied active compounds. ${ }^{18}$ It is also necessary to develop and validate an analytical method for this test, i.e., to predict whether an adequate amount of the drug is released from the formulation. ${ }^{19}$

Numerous methods of analysis have been developed for profiling green tea constituents. Reversed-phase high performance liquid chromatography (RP-HPLC) followed by UV detection is considered the gold standard ${ }^{5,20-27}$ Additional analytical techniques, such as ultra performance liquid chromatography (UPLC), ${ }^{28,29}$ gas chromatography, ${ }^{30}$ thin layer chromatography (TLC), ${ }^{31}$ Fourier transform-near infrared spectroscopy (FT-NIR), ${ }^{32}$ capillary zone electrophoresis (CZE), ${ }^{33}$ and micellar electrokinetic capillary chromatography (MEKC) ${ }^{34}$ have also been used for determining catechins. However, most of the aformentioned methods have been developed for the analysis of vegetable, drug, beverage, and extract samples. ${ }^{2,22,25}$ The challenge is even greater for the development of a method for profiling GTEs in complex matrices, such as semisolid formulations and other pharmaceutical formulations. Moreover, to develop a phytotherapic compound, it is important to validate an analytical method with accuracy, selectivity, precision, and linearity over the specific range in which an analyte is analyzed. ${ }^{19}$ In this context, the present work aims to: (i) develop and validate an RP-HPLC method for simultaneous quantification of
EGCG, CAF, and GA in transdermal formulation of green tea and (ii) determine the in vitro flux rate of EGCG across a synthetic membrane.

\section{EXPERIMENTAL}

\section{Reagents, reference standard, and materials}

Ethanol used in the preparation of the mobile phase was HPLC grade (Panreac, Spain); sodium chloride, potassium chloride, calcium chloride, magnesium sulfate, magnesium chloride, sodium sulfate, sodium bicarbonate, potassium dihydrogen phosphate, and disodium hydrogen phosphate, all were purchased from Sigma (USA). Anhydrous acetic acid and ethyl acetate (Neon, Brazil) were analytical grade. Ultrapure water, obtained from an AquaMax-Ultra 370 Series (Young Lin, Korea) (18.2 M $\mathrm{cm}$ resistivity at $25^{\circ} \mathrm{C}$ and $<10 \mathrm{ppb}$ of total organic carbon), was used throughout the analysis. As working standards, CAF (Deg, Brazil), GA, and EGCG (Sigma, USA), with purities of $101.17 \%, 102.38 \%$ and $85.14 \%$, respectively, previously standardized $(n=6)$ against the reference standards (United States Pharmacopeia (USP)) were used. GTE 95\% (Pharmanostra, Brasil) was utilized as raw material. Transdermal emulsion (Phytobase ${ }^{\circledR}$ ) was a kind gift from Fagron (Brazil). All the mobile phases and receptor media were filtered through a $0.45 \mu \mathrm{m}$ filter membrane (Sartorius, Germany) and degassed by an ultrasound apparatus (Cristófoli, Brazil) for $30 \mathrm{~min}$ before use. All volumetric glassware used were previously calibrated.

The transdermal emulsion was composed of $15 \%$ GTE (150 mg-value corrected to $157.89 \mathrm{mg}$ due to extract potency), butylated hydroxytoluene (BHT) $(0.5 \mathrm{mg})$ (All Chemistry, Brazil), potassium metabisulfite (1 mg) (Vetec, Brazil), and transdermal emulsion qs (up to $1000 \mathrm{mg}$ ). The active and antioxidant substances were accurately weighed, transferred to an agate mortar, and then geometrically homogenized with the transdermal emulsion. The product was passed through a roller mill (Fagron, USA), collected, and packed into aluminum tubes.

\section{Method development}

\section{Standard and sample solutions}

Accurately-weighed amounts of the standards were dissolved and diluted in the different mobile phases studied to obtain working solutions with the following concentrations: $\mathrm{GA}=3 \mu \mathrm{g} \mathrm{mL}^{-1}, \mathrm{CAF}=$ $6 \mu \mathrm{gL}^{-1}$, and $\mathrm{EGCG}=250 \mu \mathrm{g} \mathrm{mL}^{-1}$. Amounts of transdermal emulsion containing activity equivalent to $95 \mathrm{mg}$ of GTE were weighed, dissolved, and diluted in the same solvent mixture to obtain working solutions with a concentration of $475 \mu \mathrm{g} \mathrm{mL} \mathrm{m}^{-1}$. All solutions were left in heated $\left(\sim 50{ }^{\circ} \mathrm{C}\right)$ ultrasonic bath for $30 \mathrm{~min}$ and filtered through quantitative filter paper. The final solutions were filtered through a $0.45 \mu \mathrm{m}$ filter membrane and transferred to HPLC vials.

\section{Chromatographic conditions}

HPLC analyses were performed in a qualified and calibrated Young Lin (Korea) chromatography system composed of: quaternary pump (YL 9110), photodiode array detector (PDA-YL 9160), automatic injector (YL 9150), column compartment (YL 9130), and software controller (Clarity). Chromatographic separation was achieved using octadecylsilane $\left(\mathrm{C}_{18}\right)$ column-250 $\times 4.6 \mathrm{~mm}, 5 \mu \mathrm{m}$ particle size (Macherey-Nagel, Germany). The column was connected with a $\mathrm{C}_{18}$ pre-column, $4.0 \times 3.0 \mathrm{~mm}, 5 \mu \mathrm{m}$ (Phenomenex, USA). In order to minimize time and reagent, and optimize the factors of the chromatographic system, an experimental design approach was pursued (with focus on EGCG). The complete experimental design involved eight experiments $\left(2^{3}\right)$ and three replicates of the central point 
(a total of 11 experiments in random). ${ }^{35}$ The variables considered were: ethanol content $(10,12$, and $14 \%)$ in the mobile phase consisting of $1 \%$ anhydrous acetic acid solution, $3 \%$ ethyl acetate, and ultrapure water; column compartment temperature; and ultrasound time for sample dissolution. Some conditions, such as volume of injection loop $(20 \mu \mathrm{L})$ and flow rate gradient, were kept constant. The initial flow rate of mobile phase was $0.7 \mathrm{~mL} \mathrm{~min}^{-1}$ and maintained for 12 $\min$. Then, the flow rate was linearly increased to $1.4 \mathrm{~mL} \mathrm{~min}^{-1}$ in 5 min; this was maintained for $11 \mathrm{~min}$. Subsequently, the flow rate was allowed to decrease to $0.7 \mathrm{~mL} \mathrm{~min}^{-1}$ in $5 \mathrm{~min}$ and then maintained at the same rate for $2 \mathrm{~min}$ (total run time of $35 \mathrm{~min}$ ).

\section{Validation}

After the method development and optimization, validation tests were performed according to the International Conference on Harmonization $(\mathrm{ICH})^{36}$ and the Brazilian National Institute of Metrology, Standardization, and Industrial Quality (INMETRO) ${ }^{37}$ guidelines. The following parameters were assessed:

\section{Specificity}

The specificity of the method was obtained through the comparison of standards, sample, and blank chromatograms.

\section{Linearity}

This test was conducted by plotting three standard curves, each constructed from five concentrations (corresponding to 80, 90, 100, 110 , and $120 \%$ of the working solution concentrations). The data were statistically evaluated by analysis of variance (ANOVA) and subjected to the least-squares method to determine the correlation coefficient of the calibration curve.

\section{Limits of Detection and Quantification}

The limit of detection (LOD) and the limit of quantification (LOQ) were determined from three standard calibration curves and calculated as shown in Equation (S1) and Equation (S2) ${ }^{37}$ (Supplementary Material).

\section{Precision}

The test was designed to assess the degree of dispersion among a series of measurements obtained by the same analyst (intra-assay precision, repeatability), and between two analysts and two days (within-lab variations, intermediate precision), for solutions at $100 \%$ of the work-solution concentration. Repeatability was determined by consecutively analyzing six replicates of HPLC runs performed by a single analyst on a single day. The intermediate precision was also determined using six replicate HPLC runs, but performed in two days by different analysts. An injection precision of less than 5\% relative standard deviation (RSD) was considered appropriate.

\section{Accuracy and recovery}

The determination of accuracy was performed by the method of standard additions. The 'sample only' and the 'spiked sample' with work-solution standard concentrations of $80 \%, 100 \%$, and $120 \%$ (n $=3$ for each concentration level) were injected into the chromatograph. For each sample, the result was expressed as percentage of recovery, when compared with the analytical curve obtained from the linearity assay.

\section{Robustness}

To evaluate the significance of deliberate variations in a chosen factor $\left(\mathrm{X}_{1}\right.$ : EtOH percentage in the mobile phase; $\mathrm{X}_{2}$ : column oven temperature; $\mathrm{X}_{3}$ : ultrasound time for sample dissolution), their effects were calculated from the initial runs of experimental design. Using data from each experiment, the coefficients for determining the statistical prediction model were calculated according to Equation (S3). ${ }^{35}$ To write the equation for the fitted model, the standard errors of the coefficients were calculated using Equations (S4 and S5). ${ }^{35}$ Effects were calculated in matrix by the product of $X^{\mathrm{t}} y$, where y is a column vector containing the average results of the assays.

To estimate the standard error of an effect, the square root of the value obtained in Equation (S6) was used, and the standard error of the mean was estimated using the square root of the value obtained in Equation (S7). With the estimated standard errors, it was possible to achieve confidence intervals for the values of effects using the Student's t distribution with $95 \%$ confidence [Equation (S8)]. ${ }^{35}$

The stability of the analytical solutions was also considered as a criterion for evaluating robustness. The standard and sample solutions ( $100 \%$ concentration of work solutions), prepared in the same manner as that in the optimized method, were analyzed at $0,6,12,24$, and $48 \mathrm{~h}$. The measured concentrations of GA, CAF, and EGCG in each of these runs was compared with their respective concentrations measured in solutions prepared at time $0 \mathrm{~h}$; the response percentage was determined for the run at $48 \mathrm{~h}$.

\section{Selection of receptor media for in vitro drug release testing}

For the diffusion testing, different bio-relevant receptor media were tested to determine which one was the most suitable for EGCG. The preparation of the receptor media were according to Baert et al. $(2010)^{17}$ and the exact compositions of the same (aqueous solutions) are described in Table 1.

The solubility of EGCG in each medium (with and without 5\% bovine serum albumin (BSA)) was determined (Table 1). Aliquots

Table 1. Composition of the biorelevant receptor media used for EGCG drug release

\begin{tabular}{|c|c|c|c|}
\hline Component & $\begin{array}{l}0.01 \mathrm{~mol} \mathrm{~L}^{-1} \text { phosphate buffered saline, } \\
\text { pH } 7.4\left(\mathrm{mmol} \mathrm{L}^{-1}\right)\end{array}$ & $\begin{array}{l}\text { Artificial human sweat } \\
\qquad\left(\mathrm{mmol} \mathrm{L}^{-1}\right)\end{array}$ & $\begin{array}{l}\text { Simulated body fluid } \\
\qquad\left(\mathrm{mmol} \mathrm{L}^{-1}\right)\end{array}$ \\
\hline Sodium chloride & 138.00 & 49.96 & 136.80 \\
\hline Potassium chloride & 2.70 & - & 3.00 \\
\hline Calcium chloride & - & 0.15 & 2.50 \\
\hline Magnesium sulfate & - & 1.00 & - \\
\hline Magnesium chloride & - & - & 1.50 \\
\hline Sodium sulfate & - & - & 0.50 \\
\hline Sodium bicarbonate & - & - & 4.20 \\
\hline Potassium dihydrogen phosphate & 1.43 & 7.50 & 1.00 \\
\hline Disodium hydrogen phosphate & 8.57 & - & - \\
\hline
\end{tabular}


$(10 \mathrm{mg})$ of GTE were accurately weighed in six different $10 \mathrm{~mL}$ glass tubes, and each receptor medium was added in its respective tube. The tubes were shaken for $10 \mathrm{~min}$ and sonicated at $50{ }^{\circ} \mathrm{C}$ for 30 $\min$. They were centrifuged at $20000 \times g$, and the clear supernatant was diluted ( 1 part to 10 parts) and added into glass HPLC vials for quantification. The most suitable medium was that which solubilized EGCG to the largest extent. A new calibration curve was plotted for EGCG dissolved in this medium; eight concentrations, corresponding to $8,72,136,200,264,328,392$, and $456 \%$ of the work-solution $\left(250 \mu \mathrm{g} \mathrm{mL}^{-1}\right)$, were used in the validation.

\section{In vitro drug release}

In vitro drug release tests were carried out in $7 \mathrm{~mL}$ static vertical diffusion cells with automatic sampling (Microette Plus ${ }^{\circledR}$, Hanson Research, USA). The green tea transdermal emulsion was placed into the donor compartment $(n=6)$, while the receptor medium was put into the receptor chamber, making sure that all air under the artificial membrane was removed. The polysulfone membrane disc filters (25 mm diameter, Tuffryn ${ }^{\circledR}$, Pall Corporation, USA) were pre-washed to remove possible additives, which could affect the release of the drug from the formulation. The membranes were positioned between the cell compartments and the dermal adsorption was analyzed by the infinite dose technique. The compartments were occluded to prevent receptor medium evaporations and compositional changes. The emulsion $(300 \mathrm{mg}$ ) was applied to the surface of the membrane using a calibrated positive displacement pipette Pos-D MR-110 (Rainin, USA). The emulsion was then carefully and evenly spread to achieve complete coverage. The available diffusion area was $1.86 \mathrm{~cm}^{2}$ and a clamp was used to hold the compartments together. The receptor medium, maintained at $32 \pm 2{ }^{\circ} \mathrm{C}$ during the whole experiment, was constantly mixed by a magnetic stir bar (stirring at $600 \mathrm{rpm}$ ), except during the periods of sample collection. Aliquots $(1 \mathrm{~mL})$ were withdrawn at regular time intervals $(1,2,3,4,8$, and $12 \mathrm{~h})$ and collected into HPLC vials. The aliquots withdrawn from the receptor chamber were immediately replaced with the receptor medium at the same temperature. The EGCG concentrations were accordingly corrected for the replenishments. The quantity of the drug diffused at time $t$ $\left(\mathrm{Q}_{\text {real, }}\right)$ was calculated using Equation (S9). ${ }^{38}$

Mathematical models were applied to determine the kinetics of diffusion: cumulative amounts of drug diffusion per unit area $(\mu \mathrm{g}$ $\mathrm{cm}^{-2}$ ) were plotted against time (h) for zero-order kinetics; cumulative amounts of drug diffusion per unit area $\left(\mu \mathrm{g} \mathrm{cm}^{-2}\right)$ were plotted against square-root of time $(\sqrt{h})$ for Higuchi model; and log of the cumulative amounts of drug diffusion per unit area $\left(\log \mu \mathrm{g} \mathrm{cm}^{-2}\right)$ were plotted against time (h) for first-order kinetics. Coefficients of determination $\left(\mathrm{R}^{2}\right)$ were calculated and those with a value higher than 0.99 were considered linear. For those, steady-state diffusion flux $\left(J_{\mathrm{s}}\right)$ was determined from the linear slope of the cumulative amount of EGCG versus time curve. The lag time $\left(T_{\mathrm{L}}\right)$ represented the time required to achieve the steady-state flux.

\section{RESULTS AND DISCUSSION}

\section{Method development}

In an in vitro drug delivery study, the use of a reliable analytical method for quantification of an assayed compound, as well as for the quality control of the tested formulation, is mandatory. Although there are several reported methods for analyzing green tea constituents by RP-HPLC, ${ }^{20-27}$ some are not reproducible under the conditions available in our laboratory. The USP recommended method for the analysis of decaffeinated $\mathrm{GTE}^{9}$ has a running time of $90 \mathrm{~min}$ and considers the following chemical markers: GA, CAF, EGCG, and polyphenols (C, EC, GCG, ECG, GC, EGC, EGCG, and GCG). The newly developed method, without any loss in functionality, uses a smaller number of chemical markers and is inexpensive, reproducible and faster than the USP recommended method.

During method development, standards and samples were solubilized in mobile phase and placed in an ultrasonic bath at $50{ }^{\circ} \mathrm{C}$ for 30 min to ensure the extraction of GA, CAF, and EGCG. Separation of the components was achieved using reversed-phase chromatography. With regard to the mobile phase, acetonitrile and methanol are the most commonly used organic solvents in RP-HPLC and have often been used in the analysis of green tea catechins. ${ }^{2,22}$ However, ethanol, a biodegradable, inexpensive solvent which is less harmful to the environment, as well as to humans, was preferred. ${ }^{39}$ Therefore, an ethanol:water $(10: 90, \mathrm{v} / \mathrm{v})$ mixture was used as the mobile phase in the initial trials. Reasonable separation of the analytes of interest were observed; however, some peaks were not completely resolved until the addition of the modifier- $-1 \%$ anhydrous acetic acid $(\mathrm{pH}$ between 2.5 and 3.0). The presence of acid in the mobile phase was essential for the complete resolution of catechins. Next, ethyl acetate (3\%) was added into the ethanol/water/acetic acid solvent system. This modification decreased the run time from $160 \mathrm{~min}$ to $90 \mathrm{~min}$ and improved peak resolution.

Previously employed conditions $\left(30^{\circ} \mathrm{C}\right.$ and an isocratic elution with a flow rate of $0.7 \mathrm{~mL} \mathrm{~min}^{-1}$ ) for similar separations were tested initially. The flow rate was then optimized, thereby creating a flow gradient which led to a $55 \mathrm{~min}$ run time. This time could be reduced to 35 min when an additional $2 \%$ ethanol was added to the mobile phase.

To select of the wavelength of detection, the absorption spectra of the compounds were acquired (190-900 nm). The wavelength selected for detection under the conditions of the method was 283 $\mathrm{nm}$, as it represented the $\lambda_{\text {max }}$ for EGCG, and at this wavelength, GA and $\mathrm{CAF}$ also showed high absorption.

After selecting the above conditions, a complete experimental design $2^{3}$ with triplicate in the central point was conducted to optimize the method. Prior to this design, pilot trials were conducted in order to define the suitable ranges of variation in each parameter for the analysis of EGCG (Table 2).

Best responses for both parameters were chosen to be the conditions represented by the central point (experiments 9, 10, and 11) and they were set as:

Mobile phase $=$ water:ethanol:ethyl acetate:acetic acid (84:12:3:1, $\mathrm{v} / \mathrm{v} / \mathrm{v} / \mathrm{v})$; diluent $=$ mobile phase $(30 \mathrm{~min}$ in an ultrasonic bath at 50 ${ }^{\circ} \mathrm{C}$ ); working concentration $=3 \mu \mathrm{g} \mathrm{mL} \mathrm{m}^{-1}$ for $\mathrm{GA}, 6 \mu \mathrm{g} \mathrm{mL} \mathrm{L}^{-1}$ for $\mathrm{CAF}$, $250 \mu \mathrm{g} \mathrm{mL}^{-1}$ for EGCG, and $475 \mu \mathrm{g} \mathrm{mL}^{-1}$ for sample; column, temperature $=\mathrm{C}_{18}, 250 \times 4.6 \mathrm{~mm}, 30^{\circ} \mathrm{C}$; detection $=\mathrm{UV}, 283 \mathrm{~nm}$; flow gradient $=$ initial flow rate of $0.7 \mathrm{~mL} \mathrm{~min}^{-1}$ was maintained for 12 min and then linearly increased to $1.4 \mathrm{~mL} \mathrm{~min}^{-1}$ in $5 \mathrm{~min}$. This flow rate was maintained for the subsequent period of $11 \mathrm{~min}$ and then decreased to $0.7 \mathrm{~mL} \mathrm{~mL}^{-1}$ in $5 \mathrm{~min}$. The final flow rate was maintained for $2 \mathrm{~min}$, after which the run concluded (total run time of $35 \mathrm{~min}$ ).

USP $^{9}$ recommends that GTE should contain $>40 \%$ EGCG and $<1 \%$ GA. The manufacturer of GTE listed the content of CAF as $<2 \%$. Indeed, the GTE sample analyzed using our method does meet these specifications (42.88\% EGCG, $0.80 \% \mathrm{GA}$, and $1.54 \% \mathrm{CAF}$ ). The method was capable of quantifying $93.1 \%, 87.50 \%$, and $80.52 \%$ of EGCG, GA, and CAF, respectively, in emulsions.

\section{Validation}

As evident in Figure 2, the solvent peak does not interfere with the peaks due to the compounds of interest. There is no overlap of peaks of standard or sample and solvents; in addition, there is no overlap 
Table 2. Factors, levels, contrast coefficients matrix for the experimental design conducted to optimize the method analytical conditions, the robustness study and the respective calculated effects

\begin{tabular}{|c|c|c|c|c|c|c|c|c|c|c|}
\hline \multirow{2}{*}{ Experiment } & \multicolumn{8}{|c|}{ Matrix X } & \multicolumn{2}{|c|}{ Vectors y $*$} \\
\hline & Mean & $\mathrm{X}_{1}$ & $\mathrm{X}_{2}$ & $\mathrm{X}_{3}$ & $\mathrm{X}_{12}$ & $\mathrm{X}_{13}$ & $\mathrm{X}_{23}$ & $X_{123}$ & Assay & $\mathrm{Rt}$ \\
\hline 1 & 1 & -1 & -1 & -1 & 1 & 1 & 1 & -1 & 32.87 & 21.85 \\
\hline 2 & 1 & 1 & -1 & -1 & -1 & -1 & 1 & 1 & 36.54 & 20.09 \\
\hline 3 & 1 & -1 & 1 & -1 & -1 & 1 & -1 & 1 & 35.94 & 16.80 \\
\hline 4 & 1 & 1 & 1 & -1 & 1 & -1 & -1 & -1 & 38.29 & 16.94 \\
\hline 5 & 1 & -1 & -1 & 1 & 1 & -1 & -1 & 1 & 34.96 & 16.67 \\
\hline 6 & 1 & 1 & -1 & 1 & -1 & 1 & -1 & -1 & 39.68 & 16.67 \\
\hline 7 & 1 & -1 & 1 & 1 & -1 & -1 & 1 & -1 & 35.68 & 12.36 \\
\hline 8 & 1 & 1 & 1 & 1 & 1 & 1 & 1 & 1 & 38.48 & 12.43 \\
\hline 9 & 1 & 0 & 0 & 0 & 0 & 0 & 0 & 0 & 39.75 & 15.33 \\
\hline 10 & 1 & 0 & 0 & 0 & 0 & 0 & 0 & 0 & 39.91 & 15.33 \\
\hline 11 & 1 & 0 & 0 & 0 & 0 & 0 & 0 & 0 & 40.10 & 15.26 \\
\hline \multicolumn{11}{|c|}{ Effects on Assay } \\
\hline \multicolumn{4}{|c|}{ Mean } & \multicolumn{3}{|c|}{$37.473 \pm 0.053$} & \multicolumn{4}{|c|}{ Two-factors interactions } \\
\hline \multicolumn{4}{|c|}{ Principal effects } & & & & $\mathrm{X}_{12}$ & \multicolumn{3}{|c|}{$\mathbf{- 0 . 8 1 0} \pm 0.124$} \\
\hline \multicolumn{4}{|c|}{$\mathrm{X}_{1}$ : ultrasound dissolution of sample (min) } & \multicolumn{3}{|c|}{$\mathbf{3 . 3 8 5} \pm 0.124$} & $\mathrm{X}_{13}$ & \multicolumn{3}{|c|}{$0.375 \pm 0.124$} \\
\hline \multicolumn{4}{|c|}{$\mathrm{X}_{2}:$ Column temperature $\left({ }^{\circ} \mathrm{C}\right)$} & \multicolumn{3}{|c|}{$\mathbf{1 . 0 8 5} \pm 0.124$} & $\mathrm{X}_{23}$ & \multicolumn{3}{|c|}{$\mathbf{- 1 . 3 2 5} \pm 0.124$} \\
\hline \multirow{2}{*}{\multicolumn{4}{|c|}{$\mathrm{X}_{3}$ : Ethanol (\%) in mobile Phase }} & \multirow{2}{*}{\multicolumn{3}{|c|}{$\mathbf{1 . 2 9 0} \pm 0.124$}} & \multicolumn{4}{|c|}{ Three-factors interactions } \\
\hline & & & & & & & $\mathrm{X}_{123}$ & & $-0.150 \pm 0$ & \\
\hline
\end{tabular}

$t_{v} \cdot S_{\text {effect }}$

0.533

*Assay as \% and Rt (retention time) as min. All experiments provided good factor capacity of the chromatographic column ( $>2.0)$, symmetry of the analytical peak (>1.0) and column efficiency (number of theoretical plates/meter $>2000)$. Shadowed columns represent statistically significant effects $(p<0.05)$.

$\mathrm{X}_{1}$ : ultrasound dissolution of sample (min), (-1): $25 ;(0): 30 ;(+1): 35$.

$\mathrm{X}_{2}$ : Column temperature $\left({ }^{\circ} \mathrm{C}\right),(-1): 25 ;(0): 30 ;(+1): 35$.

$\mathrm{X}_{3}$ : Ethanol (\%) in mobile Phase, (-1): 10; (0): 12; (+1): 14.

of co-eluting peaks from the samples and standards, confirming that the method is indeed specific.

The results from the tests to investigate the linearity of the method are shown in Table 3. Calibration plots $\left(x=\mu g \mathrm{~mL}^{-1}, \mathrm{y}=\right.$ $\mathrm{mV}$ ) for the compounds of interest were drawn after analysis by the proposed method ( $n=3$, genuine replicates). The linear calibration curve was obtained after fitting the data by the least squares method and a correlation coefficient $>0.99$ was obtained. This confirmed the existence of a significant linear relationship between the two variables. ${ }^{36,37}$ For the test of lack-of-fit values, $\mathrm{F}_{\text {calculated }}$ was smaller than $\mathrm{F}_{\text {critical }}$, confirming that there was no lack-of-fit in the models (95\% confidence). ${ }^{35}$ Thus, concentrations of GA, CAF, and EGCG predicted by the model equation are likely to be close to the actual values of the samples.

The LOD and LOQ for the samples (Table 3) were calculated from the calibration plots. These values are important within the context of diffusion experiments, as one cannot predict the drug quantities which will pass through the membrane (these have to be quantified when present in the receptor media). Fortunately, method linearity, LOD, and LOQ could be confirmed when EGCG was diluted in the
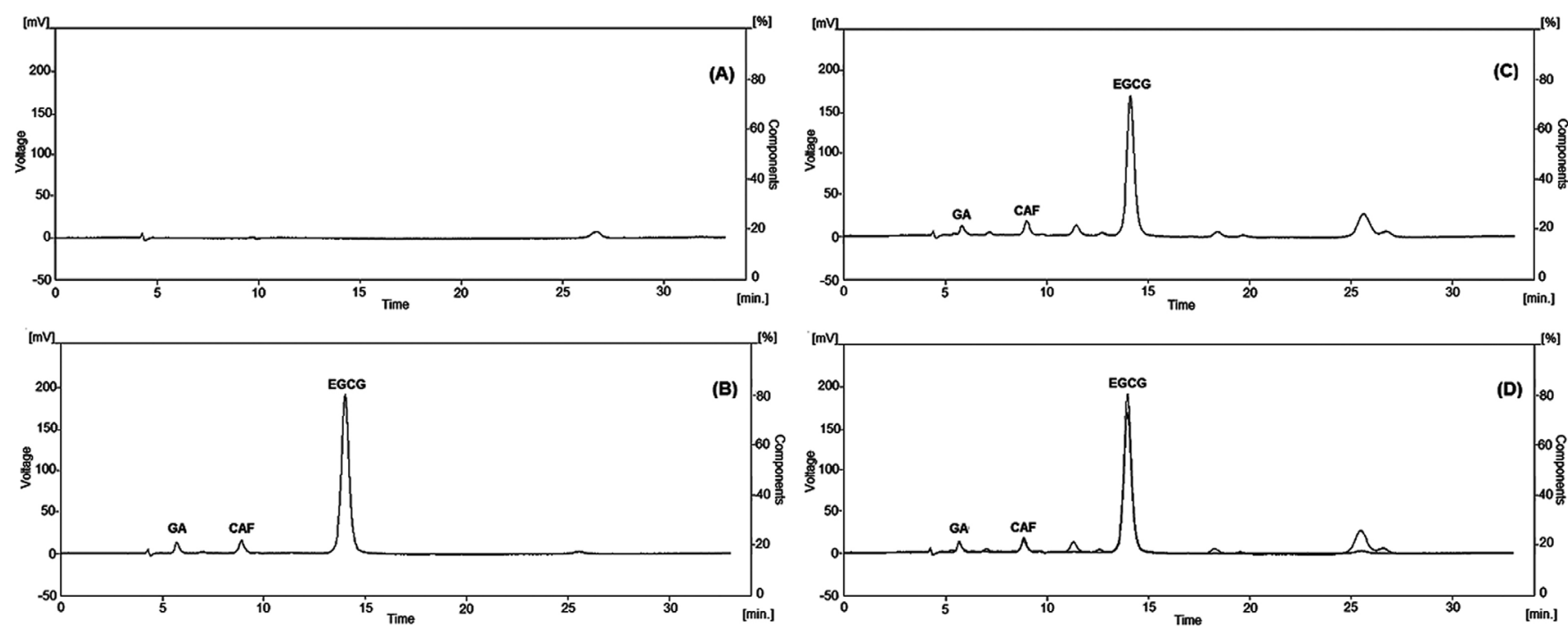

Figure 2. Chromatographic profiles obtained for the specificity test: $(A)$, blank; $(B), G A, C A F$ and EGCG standards; $(C)$, sample and (D), standard and sample overlapped 
Table 3. Results for linearity, LOD, LOQ, precision and accuracy tests

\begin{tabular}{|c|c|c|c|c|c|c|}
\hline \multirow{3}{*}{ Parameter } & & \multicolumn{4}{|c|}{ Value } & \multirow{3}{*}{$\begin{array}{l}\text { Especifi- } \\
\text { cation }\end{array}$} \\
\hline & & \multicolumn{3}{|c|}{ GTE transdermal emulsion method } & \multirow{2}{*}{$\begin{array}{c}\text { In vitro drug release } \\
\text { EGCG }\end{array}$} & \\
\hline & & GA & CAF & EGCG & & \\
\hline \multicolumn{7}{|l|}{ Linearity } \\
\hline $\begin{array}{l}\text { Linear regression } \\
\text { Equations }\end{array}$ & $\mathrm{n}=3$ & $y=53992.44 x-7001.74^{a}$ & $y=66620.62 x-27290.56^{b}$ & $y=24206.79 x-304016.95^{c}$ & $y=28128.12 x-669142.36^{d}$ & \\
\hline $\mathrm{R}^{2}$ & & 0.991 & 0.993 & 0.994 & 0.997 & $\geq 0,99$ \\
\hline $\mathrm{F}_{\text {cal }}$ Lack of fit & & $2.57^{\mathrm{e}}$ & $0.39^{\mathrm{e}}$ & $2.77^{\mathrm{e}}$ & $1.91^{\mathrm{f}}$ & \\
\hline $\operatorname{LOD}\left(\mu \mathrm{g} \mathrm{mL} L^{-1}\right)$ & $\mathrm{n}=3$ & 0.20 & 0.88 & 11.30 & 5.15 & \\
\hline $\mathrm{LOQ}\left(\mu \mathrm{g} \mathrm{mL} \mathrm{L}^{-1}\right)$ & $\mathrm{n}=3$ & 1.08 & 3.50 & 35.52 & 17.17 & \\
\hline \multicolumn{7}{|l|}{ Precision } \\
\hline $\begin{array}{l}\text { CV (\%) Intra-day, } \\
\text { First day }\end{array}$ & $\mathrm{n}=12$ & 1.75 & 1.09 & 1.36 & ------------ & $\mathrm{CV} \leq 5 \%$ \\
\hline $\begin{array}{l}\text { CV (\%) Intra-day, } \\
\text { Second day }\end{array}$ & $\mathrm{n}=12$ & 1.94 & 1.91 & 0.67 & ------------ & \\
\hline CV (\%) Inter-day & $\mathrm{n}=24$ & 2.04 & 2.39 & 1.44 & ------------ & \\
\hline \multicolumn{7}{|l|}{ Accuracy } \\
\hline Average recovery $(\%)$ & $\mathrm{n}=15$ & 99.26 & 99.25 & 98.82 & ------------ & $\begin{array}{c}98.0- \\
102.0 \%\end{array}$ \\
\hline
\end{tabular}

receptor media (Table 3) (not in the dilutant). These results confirm that the method for transdermal emulsion can be used both for quality control of semisolid products and for in vitro drug release assays.

In Table 3, the results of precision and accuracy tests are also listed. All coefficients of variation were within the recommended specification limits $(\leq 5 \%)$. The average recoveries $(98 \%-102 \%)$ do meet the acceptance criteria. ${ }^{37,39}$

In order to evaluate the robustness of the method in the determination of the main constituent (EGCG), the complete experimental design $2^{3}$ with triplicate in the central point realized was considered. The calculated values for main effects and interactions at a $95 \%$ level of confidence are shown in Table 2 . The active recovery in the method was influences by all factors and their interactions. Therefore, it is important to keep the parameters strictly fixed in order to avoid changes in the results.

A stability test was performed to evaluate if the analytes remained chemically unchanged in the analytical solutions. After $48 \mathrm{~h}$, the concentration of all analytes remained greater than $90 \%$ of those in a freshly prepared solution (Table 4). GA showed a modest increase in its concentration over time, which coincided with the slight decrease in the concentration of EGCG. This indicated that GA was a degradation product of galloylated catechins and reinforced the importance of the regulation imposed by the USP. ${ }^{9}$ However, this difference in concentration was not significant.

Considering the validations and taking all the data into account, it can be said that, from a practical standpoint, the method is valid for the intended goals.

\section{Receptor media for in vitro release testing}

The solubility of EGCG in adequate receptor media was determined (Table 5).

At high concentrations of EGCG $\left(50 \mathrm{~g} \mathrm{~L}^{-1}\right)$, the use of human serum albumin has been reported; ${ }^{40}$ thus, BSA (5\%) was added to the biorelevant media. However, EGCG could be more accurately quantified in a BSA free solution of artificial human sweat (SS). This is, then, the best media for in vitro drug release studies.

\section{In vitro drug release}

The experiments were designed taking into account important prerequisites to provide full valid kinetics data: (i) infinite dosing; (ii) usage of a membrane which does not limit the flux rate from the donor to the receptor compartments; and (iii) receptor media which

Table 4. Results for stability test of the analytical solutions

\begin{tabular}{|c|c|c|c|c|c|c|c|c|}
\hline \multirow{2}{*}{ Analytes } & \multicolumn{5}{|c|}{ Concentration $\left(\mu \mathrm{g} \mathrm{mL}^{-1}\right)$} & \multirow{2}{*}{$\begin{array}{l}\% \text { Response } \\
\text { in relation } \\
\text { to time } 0 \mathrm{~h}\end{array}$} & \multirow{2}{*}{$\begin{array}{c}0 \text { h content } \\
(\%)\end{array}$} & \multirow{2}{*}{$\begin{array}{c}48 \text { h content } \\
(\%)\end{array}$} \\
\hline & $0 \mathrm{~h}$ & $6 \mathrm{~h}$ & $12 \mathrm{~h}$ & $24 \mathrm{~h}$ & $48 \mathrm{~h}$ & & & \\
\hline \multicolumn{9}{|l|}{ Standards } \\
\hline GA & 3.69 & 3.72 & 3.72 & 3.87 & 3.94 & 106.74 & ---- & ---- \\
\hline CAF & 6.76 & 6.75 & 6.69 & 6.56 & 6.36 & 94.11 & ---- & ---- \\
\hline EGCG & 179.02 & 179.08 & 178.83 & 178.14 & 177.65 & 99.23 & ---- & ---- \\
\hline \multicolumn{9}{|l|}{ Sample } \\
\hline GA & 4.55 & 4.50 & 4.30 & 4.58 & 4.96 & 108.88 & 0.66 & 0.66 \\
\hline CAF & 4.87 & 4.86 & 4.79 & 4.70 & 4.53 & 92.92 & 1.28 & 1.27 \\
\hline EGCG & 198.34 & 183.31 & 183.26 & 182.66 & 182.27 & 91.90 & 39.50 & 39.36 \\
\hline
\end{tabular}


Table 5. Results of the maximum solubility of the EGCG in the receptor media

\begin{tabular}{lc}
\hline \multirow{2}{*}{ Receptor media } & Average solubility $\left(\mu \mathrm{g} \mathrm{mL} \mathrm{m}^{-1}, \mathrm{n}=3\right)$ \\
\cline { 2 - 2 } & EGCG \\
\hline PBS & 99.42 \\
PBS + 5 \% BSA & 140.99 \\
SS & 216.92 \\
SS + 5 \% BSA & 173.01 \\
SBF & 38.01 \\
SBF + 5 \% BSA & 8.11 \\
\hline
\end{tabular}

PBS: $0.01 \mathrm{~mol} \mathrm{~L}^{-1}$ phosphate buffered saline, $\mathrm{pH}$ 7.4. SS: artificial human sweat. SBF: simulated body fluid. BSA: bovine serum albumin.

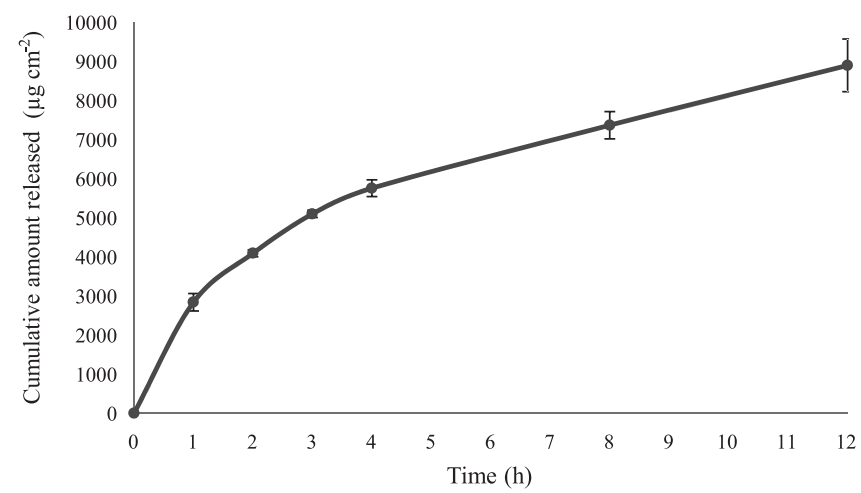

Figure 3. Release profile of EGCG. Results presented as mean \pm standard deviations $(n=6)$

Table 6. Mathematical modeling of the in vitro EGCG release kinetics

\begin{tabular}{lccccc}
\hline Drug & Mathematical & Equation & $R^{2}$ & $\begin{array}{c}J_{\mathrm{S}} \\
\left(\mu \mathrm{g} \mathrm{cm} \mathrm{c}^{-1}\right)\end{array}$ & $\begin{array}{c}T_{\mathrm{L}} \\
(\mathrm{h})\end{array}$ \\
\hline \multirow{2}{*}{ Transdermal emulsion } & Zero-order & $\mathrm{y}=509.11 \mathrm{x}+3127.8$ & 0.945 & 2382.8 & 0.09 \\
& Higuchi & $\mathrm{y}=2382.8 \mathrm{x}+733.38$ & 0.991 & \\
& First-order & $\mathrm{y}=0.0389 \mathrm{x}+3.5301$ & 0.839 & \\
\hline
\end{tabular}

$J_{\mathrm{S}}$ : steady-state flux. $T_{\mathrm{L}}$ : lag time. Results expressed as mean of six replicates.

can act as a perfect sink for the active substances and mimic the physiological conditions. ${ }^{41}$

The in vitro release profile of EGCG within the formulation was determined (Figure 3 ) and the resulting kinetic data were fitted by linear regression analysis. The data was modeled to various kinetic equations in order to identify the mechanism of drug release.

One can see that the release profile of EGCG was not linear. This indicated that its release does not follow zero-order kinetics. The data available in Table 6 confirmed that the transdermal emulsion had a $\mathrm{R}^{2}>0.99$ only when fitted for the pseudo-first-order model, also known as Higuchi's model. Thus, the release mechanism of these drugs is a diffusion process based on Fick's law and is dependent on the square root of time.

The transdermal emulsion released $8896.01 \mu \mathrm{g} \mathrm{cm}^{-2}$ of EGCG by the end of the $12 \mathrm{~h}$ experiment. This data was complemented with the determination of the flux $\left(J_{\mathrm{S}}, \mu \mathrm{g} \mathrm{cm}^{-2} \mathrm{~h}^{-1}\right)$ and lag time $\left(L_{\mathrm{T}}\right.$, h) (Table 6). About $92 \%$ of EGCG in the applied dose was released to receptor medium in $12 \mathrm{~h}$. The formulation showed a fast release, with a lag time of $5.4 \mathrm{~min}$. This release rate is formulation-specific and can be used to monitor product quality.

In vitro flux of EGCG through an artificial membrane of polysulfone (passive diffusion barrier) determined its release from an emulsion to the receiver medium. However, it is possible that the flux of EGCG is changed when it is in contact with a biological membranes, such as human skin, since resistance by stratum corneum is the major barrier to be overcome by transdermal drugs. ${ }^{42}$ Therefore, this in vitro methodology can be used a preliminary screen in the development of formulations and subsequent clinical trials. If results from in vivo testing compares well with the results of transdermal action observed in our study, the dose and the number of daily applications could be customized by the prescriber to the needs of each patient.

\section{CONCLUSION}

The RP-HPLC method developed for the quantitative determination of GA, CAF, and EGCG in green tea transdermal emulsions meets the requirements listed in the ICH and INMETRO guidelines.
The method is simple, selective, precise, and accurate. This method can be reliably used both for quality control of the green tea semisolid product and for in vitro drug release assays. In addition, the data shows that EGCG will be able to exert its biological activities systemically when used from green tea transdermal emulsion, due to its good flux rates and release percentage. Thus, this in vitro study serves as an important starting point for further in vivo studies.

\section{SUPPLEMENTARY MATERIAL}

Available with free access in PDF format at http://quimicanova. sbq.org.br.

\section{ACKNOWLEDGMENTS}

This work was supported by CNPq, CAPES, FAPEMIG, and PROPESQ/UFJF. The authors also would like to thank Fagron team for the generous donation of reagents.

\section{REFERENCES}

1. Dewik, P. M.; Medicinal natural products: a biosynthetic approach, $3^{\text {rd }}$ ed., Wiley: United Kingdom, 2009.

2. Yang, D.; Hwang, L. S.; Lin, J.; J. Chromatogr. A 2007, 1156, 312.

3. Yang, D.; Liu, Y.; Sun, M.; Zhao, L.; Wang, Y.; Chen, X.; Wei, C.; Gao, L.; Xia, T.; J Plant Physiol. 2012, 169, 163.

4. De Almeida, P. A.; Alves, M. C.; Polonini, H. C.; Dutra, L. S.; Leite, M. N.; Raposo, N. R. B.; Ferreira, A. O.; Brandão, M. A. F.; Lat. Am. J. Pharm. 2013, 32, 1082.

5. Ananingsih, V. K.; Sharma, A.; Zhou, W.; Food Res. Int. 2013, 50, 469.

6. Chacko, S. M.; Thambi, P. T.; Kuttan, R.; Nishigaki, I.; Chin. Med. 2010, $13,1$.

7. Rains, T. M.; Agarwal, S.; Maki, K. C.; J. Nutr. Biochem. 2011, 22, 1.

8. Khalaf, N. A.; Shakya, A. K.; Al-Othman, A.; El-Agbar, Z.; Farah, H.; Turk. J. Biol. 2008, 32, 51.

9. USP; The United States Pharmacopeia, 34 ${ }^{\text {th }}$ ed., United Book Press: Baltimore, 2011. 
10. Miyazaki, S. F.; Cadernos de Prospecção 2008, 1, 10.

11. Wisuitiprot, W.; Somsiri, A.; Ingkaninan, K.; Waranuch, N.; Int. J. Cosmet. Sci. 2011, 33, 572.

12. Batchelder, R. J.; Calder, R. J.; Thomas, C. P.; Heard, C. M.; Int. J. Pharm. 2004, 6, 45.

13. Dvorakova, K.; Dorr, R. T.; Valcic, S.; Timmermann, B.; Alberts D. V.; Cancer Chemother. Pharmacol. 1999, 43, 331.

14. Belo, S. E. D.; Gaspar, L. R.; Campos, P. M. B. G. M.; Marty, J. P.; Skin Pharmacol. Physiol. 2009, 22, 299.

15. Frauen, M.; Rode, T.; Rapp, C.; Steinhart, H.; Chromatographia 2002, $55,43$.

16. Prausnitz, M. R.; Langer, R.; Nat. Biotechnol. 2008, 26, 1261.

17. Baert, B.; Boonen, J.; Burvenich, C.; Roche, N.; Stillaert, F.; Blondeel, P.; Van Boxclaer, J.; De Spiegeleer, B.; J. Pharm. Pharm. Sci. 2010, 13, 218.

18. Baby, A. R.; Haroutiounian-Filho, C. A.; Sarruf, F. D.; Pinto, C. A.; Kaneko, T. M.; Velasco, M. V.; Drug Dev. Ind. Pharm. 2009, 35, 272.

19. Tiossi, F. J.; Da Costa, J. C.; Miranda, M. A.; Praça, F. S. G.; Bentley, M. V. L. B.; Bastos, J. K.; Quim. Nova 2012, 35, 2312.

20. Wang, H.; Helliwell, K.; You, X.; Food Chem. 2000, 68, 115.

21. Lin, Y. S.; Tsai, Y. J.; Tsay, J. S.; Lin, J. K.; J. Agric. Food Chem. 2003, $51,1864$.

22. Nishitani, E.; Sagesaka, Y. M.; J. Food Compos. Anal. 2004, 17, 675.

23. Sharma, V.; Gulati, A.; Ravindranath, S. D.; Kumar, V.; J. Food Compos. Anal. 2005, 18, 583.

24. Neilson, A. P.; Green, R. J.; Wood, K. V.; Ferruzzi, M. G.; J. Chromatogr. A 2006, 1132, 132.

25. Saito, S. T.; Welzel, A.; Suyenaga, E. S.; Bueno, F.; Cienc. Tecnol. Aliment. 2006, 26, 394.

26. Sander, L. C.; Bedner, M.; Tims, M. C.; Yen, J. H.; Duewer, D., L.; Porter, B.; Christopher, S. J.; Day, R. D.; Long, S. E.; Molloy, J. L.; Murphy, K. E.; Lang, B. E.; Lieberman, R.; Wood, L. J.; Payne, M. J.; Roman, M. C.; Betz, J. M.; Nguyenpho, A.; Sharpless, K. E.; Wise, S. A.; Anal. Bioanal. Chem. 2011, 402, 473.
27. Bi, W.; Li, S.; Row, K. H.; A.; Phytochem. Anal. 2011, 23, 308.

28. Spáčil, Z.; Nováková, L., Solich, P.; Talanta 2008, 76, 189.

29. Zhao, Y.; Chen, P.; Lin, L.; Harnly, J. M.; Yu, L. L.; Li, Z.; Food Chem. 2011, 126, 1269.

30. Soleas, G. J.; Yan, J.; Goldberg, D. M.; J. Chromatogr. B 2001, 757, 161.

31. Glavnik, V.; Simonovska, B.; Vovk, I.; J. Chromatogr. A 2009, 1216, 4485.

32. Chen, Q.; Zhao, J.; Chaitep, S. G. Z.; Food Chem. 2009, 113, 1272.

33. Horie, H.; Mukai, T.; Kohata, J.; J. Chromatogr. A 1997, 758, 332.

34. Peres, R. G.; Tonin, F. G.; Tavares, M. F. M.; Rodriguez-Amaya, D. B.; Food Chem. 2011, 127, 651.

35. Montgomery, D. C.; Design and Analysis of Experiments, $6^{\text {th }}$ ed., Wiley: New York, 2009.

36. ICH; Validation of Analytical Procedures: Text and Methodology Q2 (R1), International Conference on Harmonization (ICH) of Technical Requirements for Registration of Pharmaceuticals for Human Use, Geneve, 2005.

37. Instituto Nacional de Metrologia, Normalização e Qualidade Industrial (INMETRO); Orientações sobre Validação de Métodos de Ensaios Químicos; DOQ-CGCRE-008. 2003.

38. Organization for Economic Cooperation and Development (OECD); Skin absorption: in vitro method, test guideline No 428. Guidelines for the Testing of Chemicals 2004.

39. Clark, J. H.; Tavener, S. J.; Org. Process Res. Dev. 2007, 11, 149.

40. Veering, B. T.; Burm, A. G.; Souverijn, J. H.; Serree, J. M.; Spierdijk, J.; Br. J. Clin. Pharmacol. 1990, 29, 201.

41. Reichling, J.; Landvatter, U.; Wagner, H.; Kostka, K. H.; Schaefer, U. F.; Eur. J. Pharm. Biopharm. 2006, 64, 222.

42. Leichtnam, M. L.; Rolland, H.; Wüthrich, P.; Guy, R. H.; J. Pharm. Sci. 2006, 95, 1693. 